\title{
Passive energy saving strategies in vernacular architecture: parameterization of resources applied to a case study
}

\author{
V. Cristini, J. R. Ruiz Checa, J. L. Higón Calvet \\ \& J. L. Palmero Iglesias \\ Universitat Politécnica de Valéncia, Spain
}

\begin{abstract}
There are numerous passive strategies for reducing energy consumption in Spanish traditional vernacular architecture, depending on external conditions and also on the intended use of the interior of these constructions. In the case study analyzed, localized in an interior area of Spain, known as La Mancha, a set of vernacular buildings have been studied. Solar protection and solar gain, for example, are the key resources related to solar control. While cross ventilation, self-ventilation, or induced ventilation are related to the energy efficiency of the airflow. Other mechanisms identified are, for example, thermal insulation and thermal inertia of the materials. All these K-factors have been checked and parameterized in order to understand these vernacular strategies. Finally, thanks to a comparison of such resources, the study achieved a set of criteria for the use of these solutions in contemporary local architecture.
\end{abstract}

Keywords: low technology, passive design strategies, vernacular architecture.

\section{Introduction: passive energy resources in vernacular architecture}

In 1913 Adolph Loos wrote that the lesson to be learned from the architecture of peasants was no necessarily its forms but the way in which form was a direct response to function [1].

In any manifestation of vernacular architecture we can detect passive energy saving strategies and methods depending on external conditions and also on the intended use of the interior of these constructions [2]. Solar protection and solar 
gain, for example, are the key resources related to solar control. While cross ventilation, self-ventilation, or induced ventilation are related to the energy efficiency of the airflow. Other mechanisms are, for example, thermal insulation and thermal inertia of the materials. There is also a third group of strategies leading to energy savings, such as the adoption of a certain shape and geometry for the construction, the adaptation to a location or urban structure, and the use of renewable energies (wind, water, sun) [3].

\subsection{Studies on vernacular architecture in La Mancha}

La Mancha is a vast Spanish territory of more than 35,000 sq. km that encompasses much of the provinces of Toledo, Ciudad Real, Cuenca and Albacete. In addition, this region has also been key to those civilizations (Iberians, Romans, Visigoths, Berbers, Muslims, Christians) who populated it to constantly develop age-old farming activities (cereals, vineyards, olive, esparto, wool) [4].

Its elevation varies from $200 \mathrm{~m}$ at the border with Portugal's Alentejo region, to $800 \mathrm{~m}$ in the Albacete area. Despite the geographical, climatic and cultural differences, this large Iberian plateau displays common basic features.

All these historical, cultural, geographical and climatic factors and determinants have been clearly identified in this area of study (eastern part of La Mancha - Albacete), where the ten constructions under consideration are located (Fig. 1).

The traditional construction conventions of La Mancha range from traditional manor houses, inns and mills - which Cervantes already included in the world of knight-errant Quixano of La Mancha [5] - to huts, cabins, folds or farmhouses scattered across the extensive plateau.

The ever-present simplicity and sincerity of La Mancha's architecture has been reviewed by some of the leading scholars of traditional Spanish architecture, such as García Mercadal (1930), Torres Balbás (1933), Carlos Flores (1974) and Luis Feduchi (1984). They stress the importance and priority that involves providing shelter in this demanding territory, far above other priority requirements [6].

This continued attention towards the intrinsic values of La Mancha's traditional architecture has persisted, despite the lack of decorative motifs and apparent formal exuberance: La Mancha's traditional architecture is what it is. Wanting to improve it by adding eaves, imposts, jambs, balconies, baseboards..., is like dressing it up, mocking it, breaking it down [7].

As early as 1961, it was considered evident that La Mancha's vernacular architecture possesses those fundamental principles longed by the new modern currents, such as the clear adaptation to its function, the adaptation of the forms to the materials they are made of, and the subtle adaptation and harmony with the landscape [8].

Not surprisingly these constructions are the tangible reflection of centuries and civilizations settled in this vast territory.

In its materiality are deposited essences inherited from various civilizations such as the impluvium of the Roman villae (Jerez 2004), the use of indigo from 
the Berber culture, the Arabian kasbah or the tortuous nature of the Jewish quarters [7].

Behind this apparent construction harmlessness we can find intriguing lessons transmitted and improved from generation to generation.

In this sense, the present paper tries to unravel some of the energy efficiency resources that have been employed in these constructions. ... Those who walk past the vernacular architecture of La Mancha experience the intoxication of a master bullfighter's performance, whisking away that horny, scorching sun of our plateau with an unpredictable, spontaneous elegance [8].

\section{The analyzed passive energy resources of La Mancha's vernacular architecture}

There are numerous passive strategies for reducing energy consumption in La Mancha's vernacular architecture, as mentioned in the previous section. The present study focuses on the analysis and parameterization of three basic strategies employed in vernacular constructions in La Mancha.
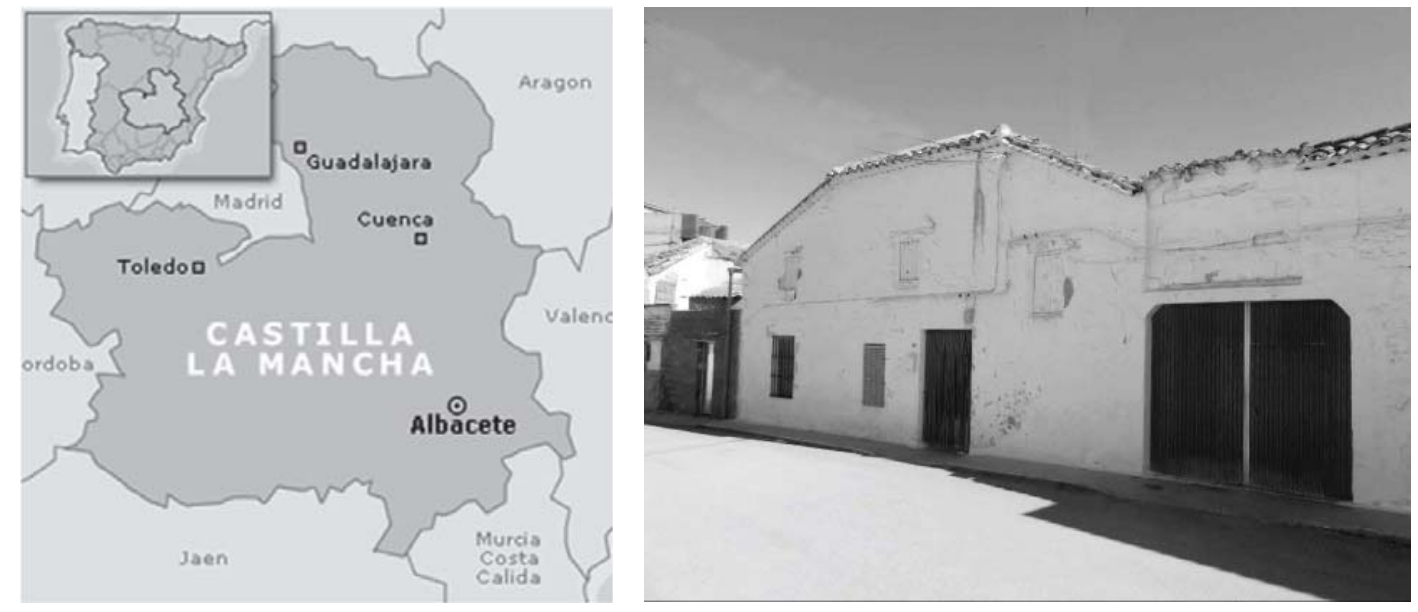

Figure 1: Area of study and example of traditional construction (Ledaña, Cuenca).

The first concerns taking advantage of the natural ventilation at the top level of the constructions, called chamber. In essence, this element specific to La Mancha's architecture refers to the space generated under the roof (sloping roofs between 20 and $25^{\circ}$ ) with a height ranging from 1 to $2 \mathrm{~m}$. In some cases, due to neighboring easements, this height is exceeded, reaching 4-5 m. The operating mechanism of this kind of ventilation consists in creating small openings in the gable walls or under eaves, which are opened in summer and closed in winter to favour or avoid hot air dissipation, respectively. Therefore, the chamber achieves two basic objectives of the functional program of La Mancha's house: one is improving the energy efficiency and thus the habitability of the lower spaces, and the other function is linked to the role of the construction as storage for crops in summer and tools in winter. 
The second energy efficiency mechanism which we aim to parameterize in this research is the use of the thermal inertia of the envelope of traditional buildings. In a typical La Mancha's housing the opaque surface takes precedence, executed mainly through two construction solutions: the first is with thick stone masonry (forty to sixty centimeters) and finish coated with lime mortar and whitewashed. The other frequent construction alternative involves the rammed earth technique, built from a masonry baseboard, most often executed in earth and gravel, not stabilized with lime.

Therefore in both cases we have walls with high thermal mass and an important energy storage capacity. This thermal mass is directly proportional to three variables: wall volume, density and specific heat. The higher these values, the greater its thermal inertia capacity. Note that this high thermal mass is the goal of energy storage, while thermal inertia is the consequence of such accumulation. Considering inertia as a body's amount of resistance to change in temperature, the use of this strategy in climates such as La Mancha's, with great fluctuations between day and night and between winter and summer, makes it the ideal building solution. However, it should be noted that the use of walls with high thermal inertia is recommended with a continued use of buildings (housing), while such thermal inertia is counterproductive when a space is used infrequently [3].

The third passive energy efficiency system or mechanism refers to openings and their features. Usually, the distribution of openings in a typical La Mancha's house is quite heterogeneous and serves functional criteria. In very few cases openings are distributed following a specific order or pattern. Furthermore, the dimensions of these openings are minimal except for the access and a small window used for ventilation. This reduced size addresses two issues: first, the minimum lighting requirements, as work in the field was carried out 'from dawn to dusk'; and secondly, it's a way of preventing solar radiation entry or loss of stored heat energy.

\section{Climate of the area of study}

As a starting point to characterize the climate of La Mancha, we used the weather data file ESP_Albacete.082800_SWEC [9].

This file contains an annual record of hourly temperature and relative humidity values for the region. The file can be opened and interpreted by the Autodesk Ecotect Analysis 2010 software, whose Weather Tool feature allows for the creation of Givoni Bioclimatic Charts [10]. Such chart is a representation of the psychrometric chart on which the maximum and minimum monthly values for temperature and relative humidity are displayed. In this representation we can see how during the months from late fall to early spring (November-March period), the maximum temperature values remain fairly low, with high relative humidities.

There are also two periods of thermal comfort (April-May and October), and a third period (June to September) with high temperatures. 
On the psychrometric chart of La Mancha, Givoni defines a comfort range $\left(20^{\circ} \mathrm{C}-26^{\circ} \mathrm{C}\right.$ and $\left.20 \%-80 \% \mathrm{RH}\right)$ as a situation in which the occupants of a building do not require any specific thermal or climatic features from it.

Outside this range, and distributed on the chart based on the values of temperature and humidity, Givoni proposes a set of bioclimatic strategies which, conceived as a building's response mechanisms to climate, allow to correct situations of discomfort.

\subsection{Bioclimatic strategies to achieve comfort status in La Mancha}

With regard to the application of the Givoni Bioclimatic Chart to the climatic data of La Mancha, the most appropriate passive bioclimatic strategies (those corresponding to the segments representing mean monthly values and that are outside the range of comfort) are called 'Natural Ventilation' and 'Thermal Inertia'. Both strategies are complementary and allow to achieve comfort status passively without external energy input.

The Natural Ventilation strategy is used to take advantage of the cool night breezes, especially in climatic situations where daytime temperatures are high and night-time temperatures drop a bit.

On the other hand, in buildings with high thermal inertia, it allows for the cooling of the building mass, thus dissipating overnight the heat stored during the day.

The Thermal Inertia strategy uses the mass of the building's envelope as a thermal moderator to achieve comfort inside the building itself. In this case, the functional physical property is the heat capacity of the materials that make up the building's envelope.

Considering the summer thermal comfort, the absorption factor of the building's envelope has to be weak (light colors, ventilated façades, top floor chambers...), the solar protection of the openings has to be effective (horizontal or vertical protection, setbacks or openings of reduced size...), and the ventilation limited to cooler hours, preferably overnight.

The various systems of inertia stabilize the temperature inside the building in response to the fluctuations of the external conditions.

\section{Method of analysis and parameterization of passive energy resources in La Mancha}

In order to obtain representative quantitative results, we selected a set of case studies with construction characteristics linked to the three bioclimatic strategies referred to above. We identified different types of vernacular constructions, all within municipalities in Eastern La Mancha (province of Albacete).

For the selection of this first sampling we visited 14 municipalities and chose 35 constructions whose common denominator was the lack of significant interventions on some of their elements (openings, walls, roofs), at least for the past 50 years [12]. 
In order to perform a rigorous and consistent data collection for these constructions, we prepared a sheet divided into two sections.

In the first we collected location and identification data, such as: house's name, cadastre reference, address, town, façade surface, plot surface, cornice height, built surface, building's date, picture and façade, orientation plain.

The second section of the sheet includes technical, construction and dimensional data. Among these, general volume and proportions and constructive details (wall section, floor section, presence of pitched roof), number of floors, wall thickness, façade finishing, openings details (Figs 2-3).

\subsection{Tools used in the analysis}

In order to rigorously establish the quantitative behavior of the aforementioned strategies, we used the CE3X tool, a software application approved by the Spanish Ministry of Industry, Energy and Tourism through the Spanish Institute for Energy Diversification and Saving (IDAE) and the Ministry of Development of Spain.

Such software is primarily designed to retrieve the energy certification of any existing building in Spain, which is a recognized document; that is, an instrument approved by the authorities for this very purpose.

The calculation methodology of said tool immediately and automatically establishes a comparison between the parameters entered against a database generated by the Ministry.

In this way, information is introduced according to different variables such as climate zone, building type, orientation, compactness, ventilation, thermal transmittance of opaque walls, wall mass, percentage of voids, transmittance of the voids, solar factors (Fig. 4).

Subsequently the software calculates the overall specific transmittance, overall specific inertia, overall specific solar factor and overall infiltration rate of the building. Once the global variables of the envelope are known, the software determines the required heating and cooling loads. Thus, the $\mathrm{CO}_{2}$ emissions of the examined building are the resulting total of the emissions from the production of heating and cooling.

\subsection{Parameters analyzed}

The purpose of this study, as already mentioned, focuses on the parameterization of three resources featured extensively in La Mancha's architecture: the presence of the under roof chamber, the high inertia of the walls, and the use of small size openings. The analysis evaluated the initial resource conditions (chamber, walls, openings), and subsequently established different scenarios in which some of the parameters (chamber height, wall thickness, solid/void ratio) were modified in order to establish a comparative analysis on the effectiveness of these bioclimatic resources. 


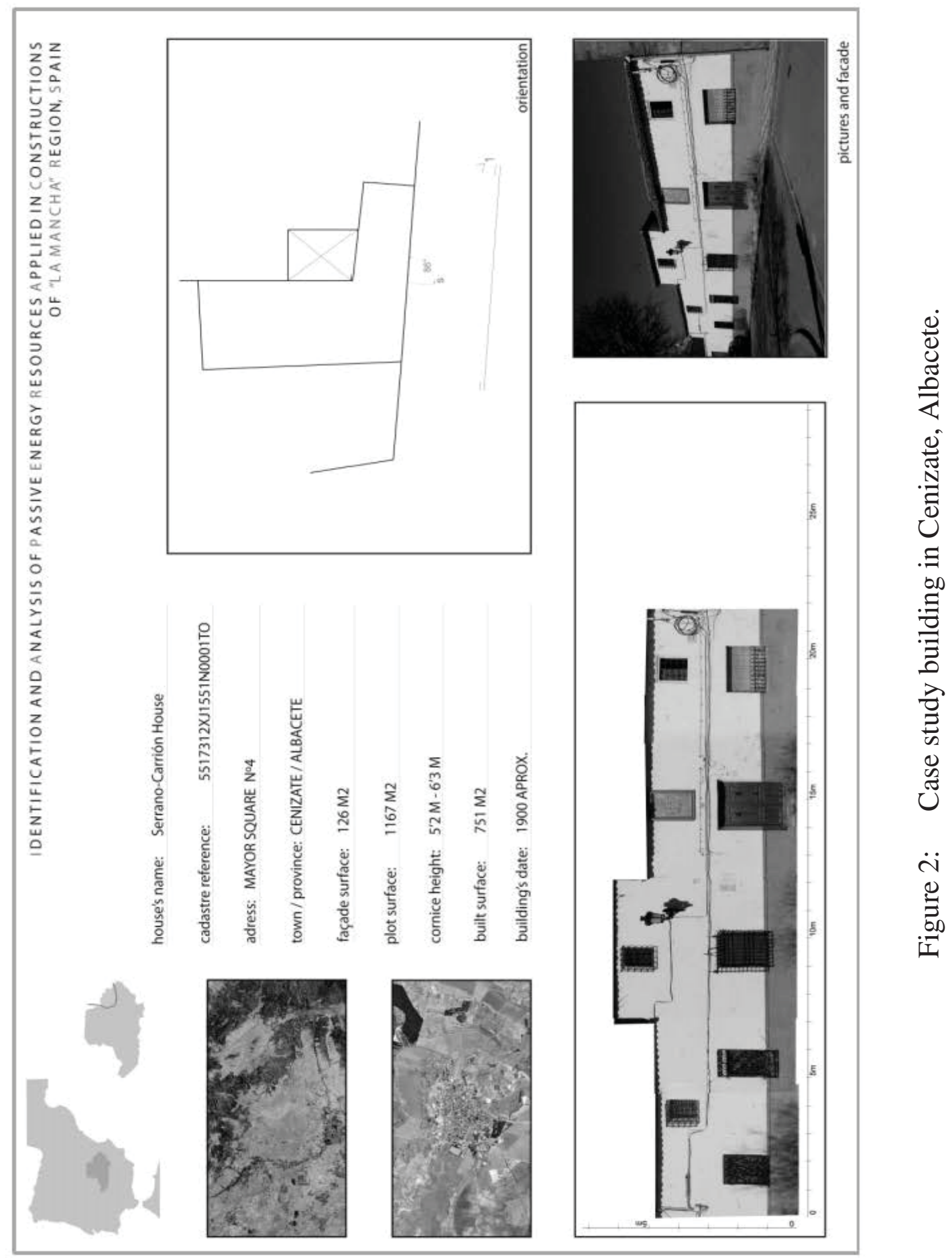




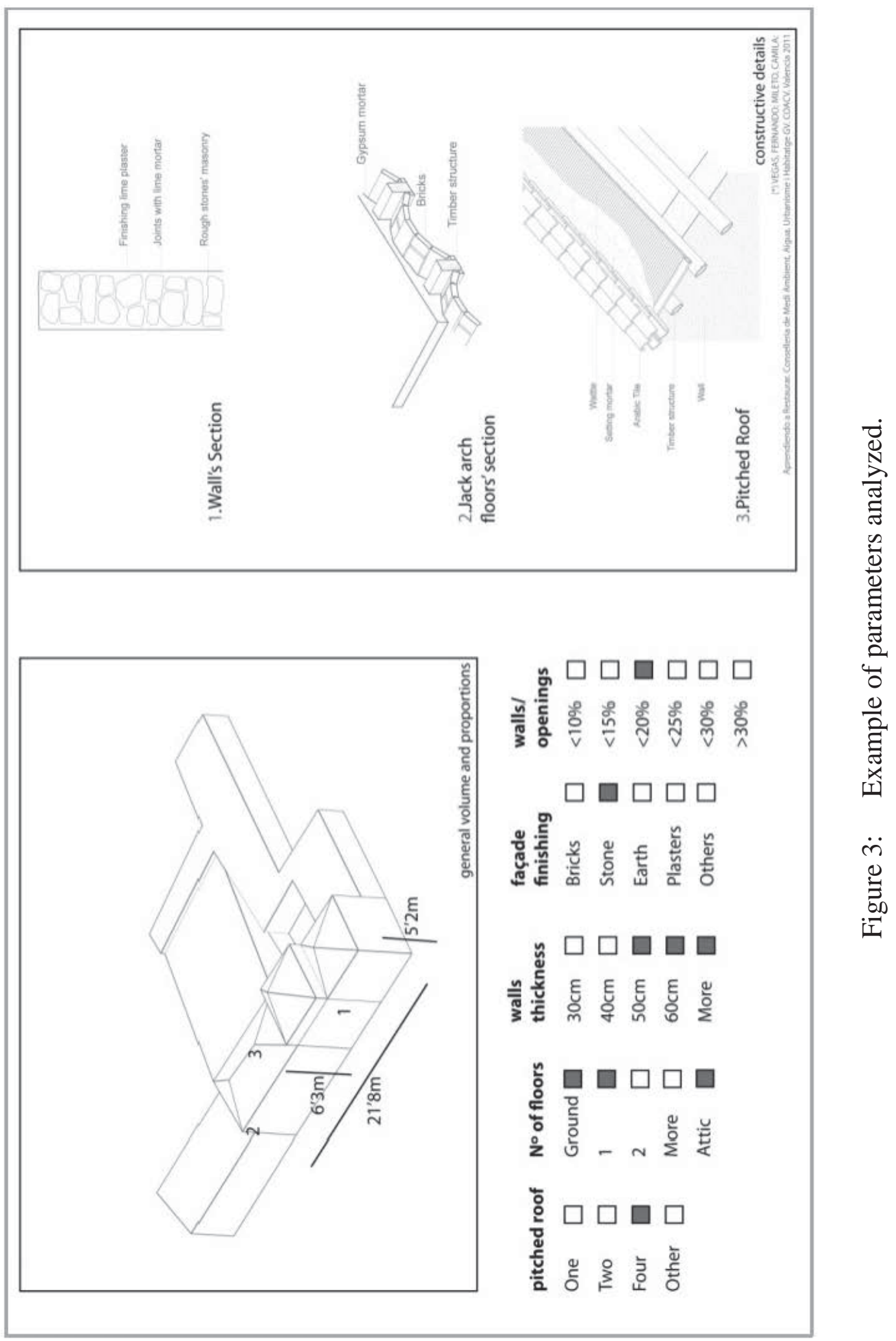




\subsubsection{The under roof chamber}

First we examined traditional under roof chambers, creating two reference scenarios where we changed the initial height of the traditional chamber $(4 \mathrm{~m}$ and $10 \mathrm{~m}$ ). Similarly, we outlined a third scenario with a current conventional roof construction solution based on polymeric thermal insulation (timber flooring, PUR thermal insulation, air chamber and curved tile). We were then able to compare and contrast the energy efficiency of the vernacular solution to the use of smaller or expanded chambers, or chambers with expensive current solutions.

\subsubsection{The wall}

Similarly, we proceeded with the study of the wall. Starting from vernacular structures, we proceeded to compare their effectiveness with similar scenarios where we varied the thickness of the wall. In the other scenario used as reference we chose to adopt a conventional wall construction solution (two ceramic sheets, air chamber and thermal insulation). With regard to the first scenario, we obtained data with three thicknesses $(10,100,200 \mathrm{~cm})$, considering that the two typical construction solutions in these vernacular constructions (masonry or rammed earth wall) were used in all cases.

\subsubsection{Openings}

As for the solid/void ratio we established three models of analysis. On the one hand, we carried out the analysis of the real scenario of traditional façades, with the original solid/void ratio. On the other hand we proposed two different solid/void ratios (1\% and $90 \%)$ as reference scenarios for the building's envelope. The unit values of transmittance for voids, carpentry and walls were maintained in all scenarios.
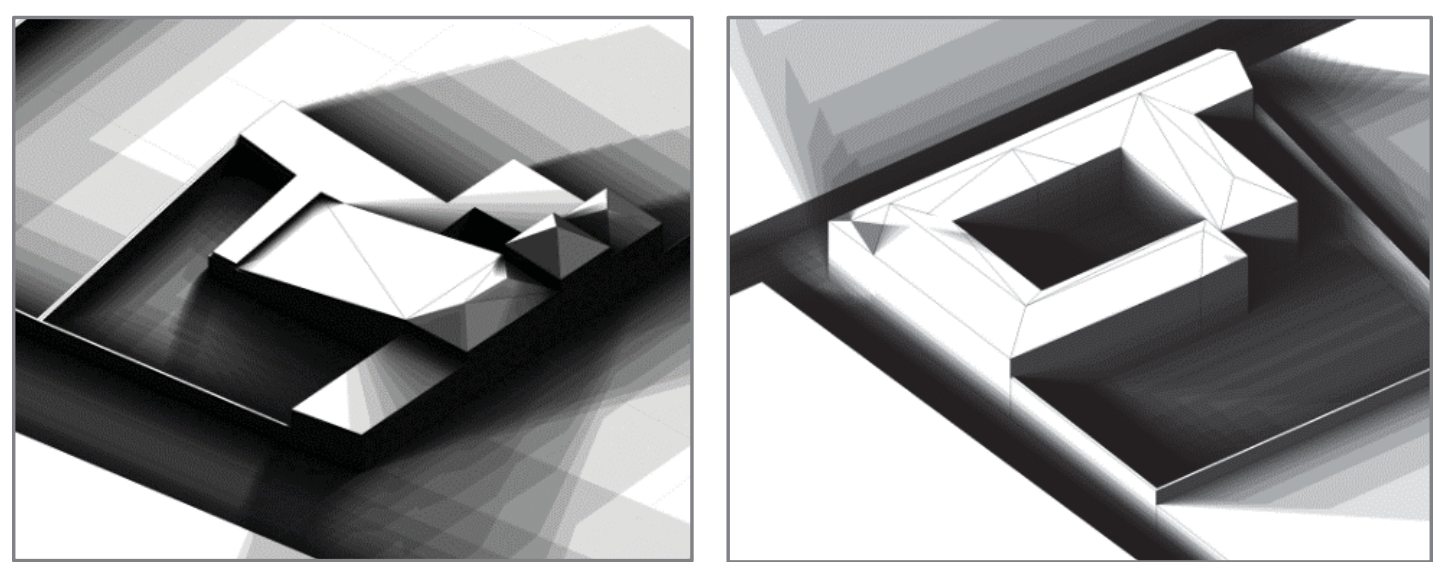

Figure 4: Examples of building orientation and solar factor study.

\section{Analysis results}

In the analysis of the under roof ventilation chamber solution, we verified that a chamber with a height between 1 and 2 meters (the typical solution in La 
Mancha's constructions) achieves values of Global Emissions of $\mathrm{Kg} \mathrm{CO}_{2} / \mathrm{m}^{2}$ per year considerably lower than those obtained with the other proposed reference scenarios. In all examined scenarios with an under roof chamber, emissions are lower than those obtained with conventional current solutions (PUR polymer thermal insulation).

An interesting aspect of the study shows how increased height (thus expanding the chamber) does not lead to significant reductions in such emissions. Note that this height increase and chamber expansion, on the other hand, would greatly increase the cost of the construction solution (more complex construction systems, with obvious increase of raw material). In the extracted results of the analysis of the different proposed scenarios for the wall and for the façade's solid/void ratio resources, we observed a trend similar to the chamber mechanism. That is, the data show how the scenarios featuring the vernacular construction solution (masonry or rammed earth wall with a thickness between 40 and $60 \mathrm{~cm}$ ) achieve lower values of Global Emissions of $\mathrm{Kg} \mathrm{CO}_{2} / \mathrm{m}^{2}$ per year than those obtained with the conventional solution actually employed (two ceramic sheets, air chamber and thermal insulation).

As for the solid/void ratio in the native vernacular solution, taking into account the original ventilation and lighting requirements, the results for the envelope's Global Emissions are equally satisfactory compared with the reference models.

\section{Conclusions}

The paper presents a first sampling aimed at establishing a method of detection and analysis of performance and efficiency dynamics of some construction strategies related to some of La Mancha's traditional buildings in good condition. In particular, thanks to this work, the results from the parameterization of vernacular energy strategies and from the comparison of such strategies with other models where some of their variables were altered, have shown an optimal response of the native solution over the scenarios with altered variables.

The validity of the resources used in vernacular constructions shows that they can be as valid or better than those provided by other construction solutions employed today.

They could be even better if we consider the energy consumption of the materials employed. Thus, through the use of the CE3X tool designed for obtaining the energy certification of existing buildings in Spain, the results of the analysis of each of the three mechanisms discussed (under roof chamber, walls with high thermal inertia, and reduced solid/void ratio) show values of global emissions of $\mathrm{Kg} \mathrm{CO}_{2} / \mathrm{m}^{2}$ per year that are lower than the values obtained by using current construction alternatives, in all cases.

Among the three strategies employed by La Mancha's vernacular architecture, providing more significant results is the one concerning an under roof chamber whose height should be between 1 and 2 meters. Also relevant are the results of the analysis of the wall envelope with optimal thickness and 
selection of materials, when comparing the values of global emissions of vernacular solutions with other current conventional solutions.

\section{Acknowledgements}

This research has been made possible thanks to the Project "Trazabilidad Histórica Y Perspectivas Para Los Materiales Sostenibles Vinculados A La Tradición Constructiva De La Comunidad Valenciana" Ayudas GV 2014/014, Conselleriad'Educació, Cultura i Esport, GVA, main researcher V. Cristini.

\section{References}

[1] Oliver, P., Built to meet needs: Cultural issues in verna-cular architecture. Oxford: Architectural Press, 2006

[2] Fathy, H. Natural energy and vernacular architecture: Principles and examples with reference to hot arid climates. Chicago: Published for the United Nations University by the University of Chicago Press, 1986

[3] Neila González, F.J., La acumulación de las energías renovables. (I), la inercia y la estabilidad térmicas en las construcciones. Madrid: Instituto Juan de Herrera Ed., 2000

[4] Feduchi, L.M., Itinerarios de arquitectura popular española. vol. 5, La Mancha, del Guadiana al mar. Barcelona: Blume, 1976

[5] Serrano, J.R, Arquitectura de "El Quijote": Casa, vidrio y humo. Añil: Cuadernos De Castilla-La Mancha, (30), 47-49, 2006

[6] García Sáez, J.F., Las ventas: Una arquitectura rural singularizada por su función. Las ventas en la provincia de Albacete. Toledo: Colegio Oficial de Arquitectos de Castilla La Mancha, 2008

[7] Fisac, M. Arquitectura popular manchega, Ciudad Real: Colegio de Arquitectos de Ciudad Real, 1985

[8] Fisac, M. La arquitectura popular española y su valor ante la arquitectura del futuro. Madrid: Ateneo, 1985

[9] Energy Plus website: http://apps1.eere.energy.gov/buildings/energyplus /weatherdata_about.cfm

[10] Givoni, B, Man, climate, and architecture. Amsterdam; New York: Elsevier, 1969

[11] Givoni, B, Climate considerations in building and urban design. New York: Van Nostrand Reinhold, 1998

[12] Ruiz Checa J.R., Cristini V., J.L. Higón, J.A. Löpez, "Identification and analysis of passive energy resources applied in constructions of "La Mancha" region, Spain" in Vernacular Architecture: Towards a Sustainable Future, Balkema Ed., London, 2014 